\title{
Anatomia da lâmina foliar de onze espécies lenhosas dominantes nas savanas de Roraima
}

\author{
Cristiane Silva FERREIRA ${ }^{1, *}$, William Silva do CARMO $^{1}$, Dalva GRACIANO-RIBEIRO ${ }^{2}$, \\ Jane Maria Franco de OLIVEIRA³, Risolandia Bezerra de MELO ${ }^{1}$, Augusto Cesar FRANCO ${ }^{1}$ \\ 1 Universidade de Brasília, Instituto de Ciências Biológicas, Departamento de Botânica, Brasília, DF, Brasil, CEP 70904-970. \\ 2 Universidade Federal de Goiás, Instituto de Ciências Biológicas, Campus Samambaia, Goiânia, GO, Brasil, CEP 70910-900. \\ ${ }^{3}$ Empresa Brasileira de Pesquisa Agropecuária, Centro de Pesquisa Agroflorestal de Roraima, Rodovia BR 174, km 8, Boa Vista, RR, Brasil, CEP: 69301-970. \\ * Autor correspondente: crisbotanica@gmail.com
}

\begin{abstract}
RESUMO
O conhecimento da anatomia da folha é crucial para o entendimento da adaptação das plantas ao ambiente. O objetivo deste estudo foi descrever a anatomia da lâmina foliar de 11 espécies lenhosas, frequentes nas savanas do extremo norte da Amazônia, com ênfase na identificação de atributos adaptativos a ecossistemas abertos, sujeitos a forte insolação e déficit hídrico sazonal. Amostras de folhas foram coletadas e processadas segundo técnicas usuais para estudos de anatomia e histoquímica. Bowdichia virgilioides, Byrsonima coccolobifolia, By. crassifolia, By. verbascifolia, Casearia sylvestris, Curatella americana, Erythroxylum suberosum, Himatanthus articulatus, Miconia albicans, Roupala montana e Xylopia aromatica apresentaram caracteres típicos de plantas heliófilas e xerófilas, como cutícula espessa e estômatos predominantes na face abaxial, além de forte investimento em tecido fotossintético. Em oito das onze espécies, o parênquima paliçádico (PP) ocupa 50\% ou mais do espaço do mesofilo. Curatella americana, mesofilo isobilateral, e Bo. virgilioides, mesofilo homogêneo, foram as espécies com maior investimento em PP $(-80 \%$ e $100 \%$, respectivamente). Além disso, destaca-se a presença de hipoderme (Bo. virgilioides e X. aromatica) ou de epiderme estratificada, densos indumentos, idioblastos cristalíferos e extensóes da bainha de feixes. Em síntese, este conjunto de atributos estruturais protege a lâmina foliar contra o excesso de luminosidade, aumenta a resistência mecânica, minimiza a transpiração e contribui para manutençáo do balanço hídrico da planta, favorecendo, portanto, o estabelecimento destas espécies nas savanas sazonais do norte da Amazônia.
\end{abstract}

PALAVRAS-CHAVE: parênquima homogêneo, savanas amazônicas, hipoderme, xerófila.

\section{Leaf anatomy of eleven dominant woody species in the savannas of Roraima}

\section{ABSTRACT}

Knowledge of the anatomical characteristics of the leaf blade is crucial to the understanding of plant adaptation to the environment. The objective of this study was to describe the leaf anatomy of 11 woody species of common occurrence in the open savannas of the northern edge of the Amazon. The focus of the study was on the identification of leaf adaptive features to cope with high irradiances and seasonal water deficits. Leaf samples were fixed and processed by the usual methods for anatomical and histochemical studies. Bowdichia virgilioides, Byrsonima coccolobifolia, By. crassifolia, By. verbascifolia, Casearia sylvestris, Curatella americana, Erythroxylum suberosum, Himatanthus articulatus, Miconia albicans, Roupala montana and Xylopia aromatica showed leaf anatomical traits typical of heliophilous and xerophilous plants such as thick cuticle, stomata prevailing on the abaxial surface, strong investment in photosynthetic tissue. In eight of the eleven species the palisade parenchyma (PP) occupied $50 \%$ or more of the mesophyll. Curatella americana, with isobilateral mesophyll, and Bo. virgilioides, with homogeneous mesophyll were the species with the highest investment in PP $(-80 \%$ and $100 \%$, respectively). Leaves were also characterized by the presence of hypodermis (Bo. virgilioides and X. aromatica) or stratified epidermis, dense indumenta, crystalliferous idioblasts and bundle sheath extensions. This distinctive assortment of anatomical traits helps protecting the leaf blade against excessive irradiances, increases mechanical strength, minimize transpiration and contribute to the maintenance of leaf water balance. Overall they favor the establishment of these species in the seasonal savannas of northern Amazon.

KEYWORDS: homogeneous parenchyma, Amazonian savannas, hypodermis, xerophilous. 


\section{INTRODUÇÃO}

As savanas naturais (lavrados) situadas no extremo norte do país ocupam uma área superior a $43.000 \mathrm{~km}^{2}$ do Estado de Roraima, que corresponde a cerca de $20 \%$ de todas as tipologias abertas do Bioma Amazônia (Barbosa e Campos 2011). Como outras formaçóes savânicas, os lavrados são caracterizados pela estrutura aberta da vegetação, solo coberto por um estrato herbáceo constituído em sua maioria por ervas e gramíneas, e sobreposto por um dossel lenhoso descontínuo (Ribeiro e Walter 1998; Barbosa et al. 2007).

Embora distantes e isoladas geograficamente, essas áreas têm elevada similaridade florística com os cerrados do Brasil Central, porém com menor nível de endemismo e de diversidade de espécies (Eiten 1972; Barbosa et al. 2007). Seis espécies são predominantes no estrato lenhoso nos lavrados de Roraima (Barbosa e Fearnside 2004; Barbosa et al. 2007), Curatella americana (Dilleniaceae), Bowdichia virgilioides (Fabaceae), Byrsonima crassifolia, By. coccolobifolia, By. verbascifolia (Malpighiaceae) e Himatanthus articulatus (Apocynaceae). Entre estas, By. coccolobifolia, By. crassifolia e Cu. americana, típicas de ambientes secos e sujeitos à passagem do fogo (Foldats e Rutkis 1975; Barbosa e Fearnside 2004), são consideradas espécies-chave, pois juntas representam cerca de $60-70 \%$ do total de indivíduos que compóem a vegetação arbórea, e são responsáveis por mais de $80 \%$ da biomassa arbórea acima do solo (Barbosa et al. 2007). Schaefer e Dalrymple (1996) associam a presença dominante de Byrsonima spp. e Cu. americana à geologia do solo, que apresenta características semiáridas, provavelmente devido a eventos climáticos (longos períodos secos) ocorridos na região durante o Quaternário e que, independente da elevada precipitação atual, vestígios da história geológica associados com a forte sazonalidade das chuvas, estariam favorecendo a persistência de uma vegetação xerófila na região.

Apesar da singularidade, da dimensão das áreas de lavrados, e da existência de diversos trabalhos sobre a origem e diversidade da flora destes locais (Miranda e Absy 2000; Barbosa et al. 2007; Meneses et al. 2013), pouco se conhece sobre a anatomia das espécies nativas, especialmente lenhosas, ocorrendo nesses ambientes. O conhecimento sobre a anatomia das plantas, além de subsídio para a taxonomia e de refletir aspectos filogenéticos, é essencial para o melhor entendimento das adaptaçóes das plantas a um determinado ambiente. A estrutura e organização da lâmina foliar afeta os processos de regulaçáo e a magnitude dos fluxos foliares de água e $\mathrm{CO}_{2}$. Alteraçóes no tamanho e na forma da lâmina foliar, bem como seu grau de esclerofilia, são características que estão comumente associadas com a história de vida, distribuição da espécie e requerimentos de recursos pelas plantas (Metcalfe e Chalk 1950; Eiten 1972; Bieras e Sajo 2009) e, portanto, estão sob forte pressão de seleção. O objetivo deste estudo foi descrever a anatomia da lâmina foliar de 11 espécies lenhosas, frequentes nas savanas do extremo norte da Amazônia, com ênfase na identificação de atributos adaptativos a ecossistemas abertos, sujeitos a forte insolação e déficit hídrico sazonal.

\section{MATERIAL E MÉTODOS}

\section{Áreas de estudo}

O estudo foi realizado em duas áreas de parcelas permanentes do Programa de Pesquisa em Biodiversidade (PPBio), o Campo Experimental Água Boa - CEAB $\left(02^{\circ} 39^{\prime} 48^{\prime} \mathrm{N}, 060^{\circ} 52^{\prime} 04^{\prime \prime} \mathrm{W}\right)$, pertencente à Empresa Brasileira de Pesquisa Agropecuária (Embrapa Roraima), situado à margem esquerda da BR-174, km 25, sentido Boa Vista-Manaus, e o Campo Experimental Monte Cristo/ Campus Cauamé $\left(02^{\circ} 56^{\prime} 47^{\prime} \mathrm{N}, 60^{\circ} 43^{\prime} 02^{\prime} \mathrm{W}\right)$, localizado no Centro de Ciências Agrárias da Universidade Federal de Roraima (CCA/UFRR), na BR 174, sentido Boa VistaVenezuela. As duas áreas são constituídas de paisagens típicas das savanas locais (lavrados), formando um grande mosaico de ambientes gramíneo-lenhosos, parques e arborizados (Barbosa et al. 2007; Araújo e Barbosa 2007). A precipitação média anual da região é de $1600 \mathrm{~mm}$, com uma estação seca bem definida, entre os meses de dezembro a março (Barbosa et al. 2007). Os solos são bem drenados e apresentam ampla diversidade, em que se destacam as diferentes classes de latossolos (Araújo e Barbosa 2007). No CEAB, há a predominância de Latossolo Amarelo, textura areno-argilosa. O Campus Cauamé está em uma área de Latossolo Vermelho distrófico, textura argilo-arenosa.

\section{Espécies estudadas}

As espécies escolhidas para o estudo fazem parte do estrato arbóreo-arbustivo, são do tipo fotossintético $\mathrm{C}_{3}$, e estão entre as mais representativas nas savanas de Roraima (Miranda e Absy 2000; Araújo e Barbosa 2007; Barbosa et al. 2007): Bowdichia virgilioides Kunth. (Fabaceae), Byrsonima coccolobifolia Kunth., By. crassifolia Kunth, By. verbascifolia Rich. (Malpighiaceae), Casearia sylvestris Swartz (Salicaceae), Curatella americana L. (Dilleniaceae), Erythroxylum suberosum St. Hil (Erythroxylaceae), Himatanthus articulatus (Vahl) Woodson (Apocynaceae), Miconia albicans Sw. (Melastomataceae), Roupala montana Aubl. (Proteaceae) e Xylopia aromatica Mart. (Annonaceae).

\section{Análises anatômicas}

Para cada espécie, três indivíduos foram selecionados no campo para coleta de material vegetal. Foi coletada a segunda ou terceira folha totalmente expandida, a partir do ápice do ramo. As folhas foram fixadas em FAA 50\% (formaldeído, ácido acético, etanol 50\%, 1:1:18 v/v) por $24 \mathrm{~h}$ (Johansen 
1940), depois armazenadas em etanol $70 \%$ e transportadas para o Laboratório de Anatomia Vegetal da Universidade de Brasília, Distrito Federal, onde se procederam as análises. A descrição da epiderme foi realizada a partir de secçôes retiradas do ápice, nervura central (região mediana) e base das folhas, dissociadas em solução de ácido nítrico 30\% e soluçâo de Franklin (Jensen 1962; Johansen 1940). O material obtido foi corado com safranina e as lâminas foram montadas utilizando resina sintética (Paiva et al. 2006). Para as análises histológicas, secçôes de cortes transversais foram feitas à mão livre, clarificadas em solução de hipoclorito de sódio 20\% (Kraus e Arduin 1997) e coradas com soluçóes aquosas azul de alciáo 4\% e safranina 1\% (Luque et al.1996). As secçóes foram montadas entre lâmina e lamínula, após serem desidratadas em série etílica, diafanizadas em acetato de butila e montadas em resina sintética (Johansen 1940; Paiva et al. 2006). Para os testes histoquímicos, secçôes transversais das lâminas foliares foram submetidas à solução de dicromato de potássio $10 \%$ para evidenciar compostos fenólicos, e a ácido acético glacial para verificar a composiçâo química dos cristais, seguindo a metodologia de Kraus e Arduin (1997). As observaçôes e a documentação fotográfica das lâminas foram feitas em microscópio óptico (Leica DM 750, Microsystems Ltd., Switzerland), com câmera digital (Leica ICC50 HD, Microsystems Ltd., Switzerland) acoplada. As imagens foram analisadas com o auxílio do software Leica LAZ EZ versão 2.0.0. A descriçáo anatômica foi feita de acordo com Metcalfe e Chalk (1950) e Evert (2006).

\section{RESULTADOS}

$\mathrm{Na}$ superfície das folhas, em vista frontal, a forma das células epidérmicas comuns (ordinárias) das espécies estudadas difere entre si (Tabela 1). Na face adaxial de By. coccolobifolia (Figura 1A), By. crassifolia e By. verbascifolia as células, de paredes delgadas, possuem contorno quadrado a irregular, enquanto as células da face abaxial são menores, de formato retangular a irregular. Casearia sylvestris e Cu. americana possuem células epidérmicas com parede delgada, de formato retangular a arredondado, em ambas as faces. Células com esse formato também são predominantes na face adaxial de $H$. articulatus e $X$. aromatica. Porém, na face abaxial, as células de $H$. articulatus possuem formato alongado, e as de $X$. aromatica arredondado. Células de formato retangular constituem a face adaxial de E. suberosum e, nesta espécie, a presença de papilas em forma de cúpula na face abaxial (Figura 1B) dificultou a visualização e a caracterização das células epidérmicas. Células de contorno quadrado a arredondado são predominantes na face adaxial de Bo. virgilioides, $M$. albicans e $R$. montana, enquanto na face abaxial dessas espécies, as células apresentam contorno quadrado a irregular (Figura 1C). Nas células epidérmicas comuns da face adaxial de $B y$. coccolobifolia (Figura 1D), H. articulatus e R. montana, são observados abundantes cristais de oxalato de cálcio na forma de monocristais prismáticos e/ou drusas, e em Ca. sylvestris, os cristais observados possuem a forma de ráfides.

Tricomas tectores estáo presentes na lâmina foliar de oito espécies (Tabela 1), sendo que em cinco delas, By. crassifolia, By. verbascifolia, Bo. vigilioides, $C u$. americana e $X$. aromatica, estas estruturas ocorrem em ambas as faces. Nas espécies de $B y$. crassifolia (Figura 1E) e By. verbascifolia (Figura 1F), os tricomas são unicelulares ramificados em forma de $T$, com braços desiguais. Tricomas unicelulares simples ocorrem na epiderme destas espécies, mas são raros e observados apenas na face adaxial. Bowdichia virgilioides e $\mathrm{Cu}$. americana apresentam tricomas pluricelulares, observados com maior frequência na face abaxial. Em Bo. virgilioides, os tricomas são longos e com uma célula na base, enquanto em $\mathrm{Cu}$. americana sáo do tipo estrelado (Figura $1 \mathrm{G})$, alguns com braços longos e outros de braços curtos. Xylopia aromatica possui tricomas com parede espessa, unicelular ou pluricelular. Nas espécies $C a$. sylvestris, $M$. albicans e $R$. montana, os tricomas ocorrem apenas em uma das faces. Em Ca. sylvestris, os tricomas são unicelulares e estão presentes na face adaxial, preferencialmente na regiáo da nervura principal, sendo escassos no restante da lâmina foliar. Em M. albicans, os tricomas são observados em abundancia na face abaxial, longos e ramificados (Figura 1H). Roupala montana possui tricomas na face abaxial e esses são constituídos de duas a cinco células na base. A epiderme é glabra em By. coccolobifolia, E. suberosum e H. articulatus.

Nove espécies são hipoestomáticas (Tabela 2). Com exceção de $M$. albicans, todas possuem estômatos paracíticos (Tabela 1), situados no mesmo nível das células epidérmicas. Em $M$. albicans, os estômatos são anomocíticos, nivelados a levemente projetados em relaçáo às demais células epidérmicas (Figura 2A). Na epiderme de duas destas espécies, foi observado mais de um tipo de estômato, Bo. virgilioides que apresentou o tipo anomocítico, e By. coccolobifolia os tipos anomocítico (Figura 2B) e tetracítico. Em Cu. americana os estômatos se encontram densamente agrupados entre as nervuras (Figura 2C). As espécies By. coccolobifolia, By. crassifolia, By. verbascifolia, Cu. americana e $R$. montana apresentam uma projeçấo da parede periclinal externa das células-guarda, que delimita uma pequena câmara supraestomática formada pela presença de proeminentes cristas supraestomáticas (Figura 2D).

Duas espécies, $C a$. sylvestris e $H$. articulatus, são anfiestomáticas, com os estômatos situados no mesmo nível das células epidérmicas. Casearia sylvestris possui estômatos paracíticos e anisocíticos na face abaxial, enquanto na face adaxial, além destes, foi identificado o tipo tetracítico. Himatanthus articulatus possui estômatos anisocíticos em ambas as faces (Tabela 1), entretanto, na face adaxial, a presença dessas estruturas é rara e está restrita à região ao longo das nervuras. 
Tabela 1. Tricomas predominantes, formas das células epidérmicas comuns (ordinárias) e tipos de estômatos na lâmina foliar de 11 espécies lenhosas das savanas de Roraima. $A B=$ abaxial, $A D=$ adaxial.

\begin{tabular}{|c|c|c|c|c|c|c|c|c|}
\hline \multirow[t]{2}{*}{ Família/Espécie } & \multicolumn{4}{|c|}{ TRICOMAS } & \multicolumn{2}{|c|}{$\begin{array}{l}\text { FORMA DAS CÉLULAS } \\
\text { EPIDÉRMICAS COMUNS }\end{array}$} & \multicolumn{2}{|c|}{ ESTÔMATOS } \\
\hline & tipo & unicelular & pluricelular & face & face abaxial & face adaxial & face abaxial & face adaxial \\
\hline \multicolumn{9}{|l|}{ Fabaceae } \\
\hline Bowdichia virgilioides & tectores & & simples & $\mathrm{AB} / \mathrm{AD}$ & $\begin{array}{l}\text { quadrada a } \\
\text { irregular }\end{array}$ & $\begin{array}{l}\text { quadrada a } \\
\text { arredondada }\end{array}$ & $\begin{array}{l}\text { paracítico, } \\
\text { anomocítico }\end{array}$ & \\
\hline \multicolumn{9}{|l|}{ Malpighiaceae } \\
\hline $\begin{array}{l}\text { Byrsonima } \\
\text { coccolobifolia }\end{array}$ & & & & & $\begin{array}{l}\text { retangular a } \\
\text { irregular }\end{array}$ & $\begin{array}{l}\text { quadrada a } \\
\text { irregular }\end{array}$ & $\begin{array}{c}\text { paracítico, } \\
\text { anomocítico, } \\
\text { tetracítico }\end{array}$ & \\
\hline Byrsonima crassifolia & tectores & $\begin{array}{l}\text { ramificado em } \\
\text { forma de T }\end{array}$ & & $A B / A D$ & $\begin{array}{l}\text { retangular a } \\
\text { irregular }\end{array}$ & $\begin{array}{c}\text { quadrada a } \\
\text { irregular }\end{array}$ & paracítico & \\
\hline $\begin{array}{l}\text { Byrsonima. } \\
\text { verbascifolia }\end{array}$ & tectores & $\begin{array}{l}\text { ramificado em } \\
\text { forma de T }\end{array}$ & & $A B / A D$ & $\begin{array}{l}\text { retangular a } \\
\text { irregular }\end{array}$ & $\begin{array}{l}\text { quadrada a } \\
\text { irregular }\end{array}$ & paracítico & \\
\hline \multicolumn{9}{|l|}{ Salicaceae } \\
\hline Casearia sylvestris & tectores & simples & & $A D$ & $\begin{array}{l}\text { retangular a } \\
\text { arredondada }\end{array}$ & $\begin{array}{l}\text { retangular a } \\
\text { arredondada }\end{array}$ & $\begin{array}{l}\text { paracítico, } \\
\text { anisocítico }\end{array}$ & $\begin{array}{c}\text { paracítico, } \\
\text { anisocítico, } \\
\text { tetracítico }\end{array}$ \\
\hline \multicolumn{9}{|l|}{ Dilleniaceae } \\
\hline Curatella americana & tectores & & estrelado & $A B / A D$ & $\begin{array}{l}\text { retangular a } \\
\text { arredondada }\end{array}$ & $\begin{array}{l}\text { retangular a } \\
\text { arredondada }\end{array}$ & paracítico & \\
\hline \multicolumn{9}{|l|}{ Erythroxylaceae } \\
\hline Erytroxylum suberosum & & & & & papilosa & retangular & paracítico & \\
\hline \multicolumn{9}{|l|}{ Apocynaceae } \\
\hline Himatanthus articulatus & & & & & alongada & $\begin{array}{l}\text { retangular a } \\
\text { arredondada }\end{array}$ & anisocítico & anisocítico \\
\hline \multicolumn{9}{|l|}{ Melastomataceae } \\
\hline Miconia albicans & tectores & & estrelado & $A B$ & $\begin{array}{l}\text { quadrada a } \\
\text { irregular }\end{array}$ & $\begin{array}{l}\text { quadrada a } \\
\text { arredondada }\end{array}$ & anomocítico & \\
\hline \multicolumn{9}{|l|}{ Proteaceae } \\
\hline Roupala montana & tectores & simples & & $A B$ & $\begin{array}{l}\text { quadrada a } \\
\text { irregular }\end{array}$ & $\begin{array}{l}\text { quadrada a } \\
\text { arredondada }\end{array}$ & paracítico & \\
\hline \multicolumn{9}{|l|}{ Annonaceae } \\
\hline Xylopia aromatica & tectores & simples & simples & $A B / A D$ & arredondada & $\begin{array}{l}\text { retangular a } \\
\text { arredondada }\end{array}$ & paracítico & \\
\hline
\end{tabular}

O corte transversal mostrou que todas as espécies possuem uma cutícula espessa cobrindo a face adaxial, sendo que em By. coccolobifolia, By. crassifolia (Figura 1E), By. verbascifolia, Ca. sylvestris, $C u$. americana, $H$. articulatus, $R$. montana e $X$. aromatica, o espessamento da cutícula é observado também na face abaxial. Em H. articulatus, a cutícula é estriada (Figura 2E). Quanto à estratificação da epiderme, em By. coccolobifolia, By. crassifolia (Figura 1E), By. verbascifolia (Figura 1F) e Cu. americana, a epiderme é uniestratificada na face abaxial e biestratificada não contínua na face adaxial. Sete espécies, Bo. virgilioides, Ca. sylvestris, E. suberosum, $H$. articulatus, $M$. albicans, $R$. montana $X$. aromatica possuem a epiderme estratificada nas duas faces. A presença de uma hipoderme foi identificada na face abaxial de Bo. virgilioides (Figura 3A) e na face adaxial de $X$. aromatica (Figura 3B).
A organização do mesofilo é isobilateral em $B y$. coccolobifolia, By. crassifolia (Figura 1E), By. verbascifolia (Figura 1F) e Cu. americana (Figura 1G). O parênquima paliçádico em By. coccolobifolia e By. crassifolia é formado por duas camadas de células, dispostas em direção perpendicular a cada face (abaxial e adaxial), sendo a camada mais externa da face adaxial alongada e compactada. O parênquima lacunoso possui até três camadas de células braciformes com paredes delgadas. By. verbascifolia e Cu. americana (Figura $1 \mathrm{G}$ ) possuem duas camadas de células paliçádicas perpendiculares à face adaxial, e uma camada perpendicular à face abaxial. Porém, em $B y$. verbascifolia, as células paliçádicas são menores (ocupam $50 \%$ do mesofilo) e os espaços intercelulares maiores, enquanto em $\mathrm{Cu}$. americana as células paliçádicas são longas e preenchem cerca de $80 \%$ do mesofilo (Tabela 2). Byrsonima verbascifolia possui cinco camadas de células no parênquima lacunoso, 

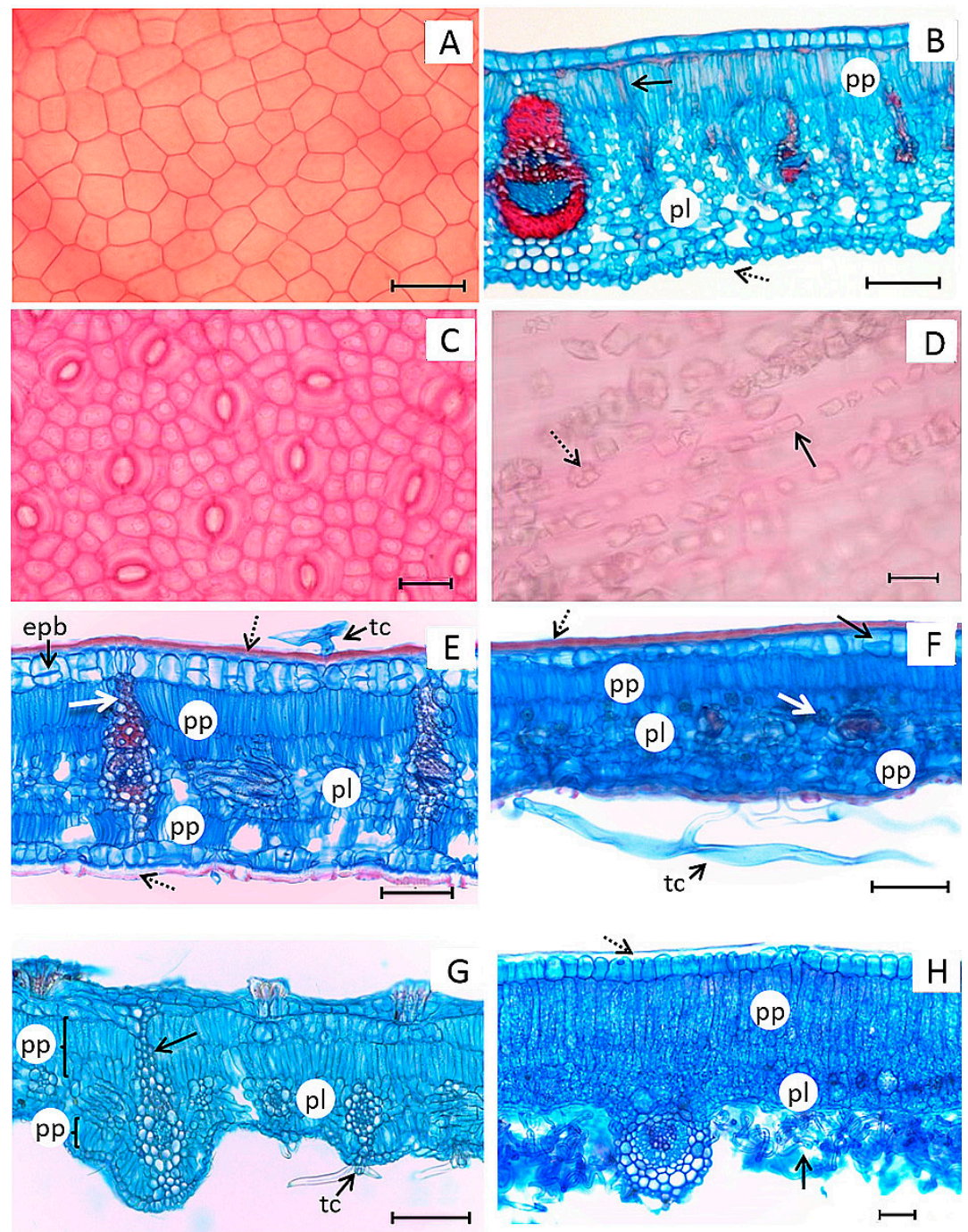

Figura 1. Vista frontal (A, C e D) ou cortes transversais (B, E-H) mostrando: (A) face adaxial de Byrsonima coccolobifolia com células epidérmicas de contorno quadrado a irregular, de paredes delgadas; (B) esclereídes na face adaxial (seta contínua) e células papilosas na face abaxial (seta tracejada) no mesofilo de Erytroxylum suberosum; (C) face abaxial de Roupala montana, com células de formato quadrado a irregular e estômatos paracíticos; (D) numerosos cristais prismáticos (seta contínua) e drusas (seta tracejada) na face adaxial de Byrsonima coccolobifolia; (E) cutícula espessa (seta tracejada), epiderme biestratificada não contínua, mesofilo isobilateral, feixes vasculares com extensões da bainha (seta branca) em Byrsonima crassifolia; (F) cutícula espessa (seta tracejada), epiderme biestratificada não contínua (seta contínua), presença de drusas (seta branca) no mesofilo isobilateral, tricoma unicelular ramificado em forma de T na face abaxial de Byrsonima verbascifolia; (G) arranjo das células paliçádicas constituindo mesofilo isobilateral (chaves), feixes vasculares com extensões da bainha (seta contínua) e tricomas estrelados em Curatella americana; $(\mathrm{H})$ cutícula espessa na face adaxial (seta tracejada) e densos indumentos (seta contínua) na face abaxial de Miconia albicans. epb = epiderme biestratificada, $\mathrm{pl}=$ parênquima lacunoso, $\mathrm{pp}=$ parênquima paliçádico, tc $=$ tricomas. Barras $=20$ $\mu \mathrm{m}(\mathrm{A}, \mathrm{C}, \mathrm{D}, \mathrm{H}) ; 50 \mu \mathrm{m}(\mathrm{B}, \mathrm{E}, \mathrm{F}, \mathrm{G})$. Esta figura é colorida na versão eletrônica.

enquanto Cu. americana possui de duas a três camadas de células. Nas duas espécies, as células do parênquima lacunoso são de formato irregular com paredes delgadas.

O mesofilo é dorsiventral em Ca. sylvestris, E. suberosum (Figura 1B), $H$. articulatus, M. albicans, $R$. montana e $X$. aromatica (Figura 3B). O parênquima paliçádico de $\mathrm{Ca}$. sylvestris e $H$. articulatus é composto por duas camadas de células alongadas, e o parênquima lacunoso por cinco a seis camadas de células irregulares. As espécies E. suberosum e $X$. aromatica possuem de duas a três camadas de células paliçádicas alongadas. No entanto, o parênquima lacunoso de E. suberosum é composto por até sete camadas de células braciformes, enquanto $X$. aromatica possui até cinco camadas de células irregulares com espaços intercelulares evidentes. Por outro lado, M. albicans apresenta apenas uma camada de parênquima paliçádico formado de células longas e largas, mas 
Tabela 2. Principais caracteres anatômicos da lâmina foliar de 11 espécies lenhosas das savanas de Roraima. $(+)=$ presença, $(-)=$ ausência, $A B=$ abaxial, $\mathrm{AD}=$ adaxial, Hipo = hipoestomática, Anfi = anfiestomática, Iso = isobilateral, Homo = homogêneo, Dorsi = dorsiventral, $\mathrm{PP}=$ parênquima paliçádico, $\mathrm{PL}$ = parênquima lacunoso, $\mathrm{IC}=$ idioblastos cristaliferos, $\mathrm{C}=$ cristais, $\mathrm{D}=$ drusas, $\mathrm{Par}=$ parenquimática, Escl $=$ esclerenquimática, $\mathrm{AF}=\mathrm{arco}$ fechado, $\mathrm{AA}$ $=$ arco aberto, $\mathrm{Co}=$ colateral, $\mathrm{Bi}=$ bicolateral.

\begin{tabular}{|c|c|c|c|c|c|c|c|c|c|c|c|c|}
\hline \multirow{2}{*}{ Família/Espécie } & \multirow{2}{*}{$\begin{array}{l}\text { Cutícula } \\
\text { espessa }\end{array}$} & \multicolumn{2}{|c|}{ EPIDERME } & \multicolumn{5}{|c|}{ MESOFILO } & \multirow{2}{*}{$\begin{array}{c}\text { NERVURA } \\
\text { SECUNDÁRIA } \\
\text { extensão da bainha } \\
\text { de feixes }\end{array}$} & \multicolumn{3}{|c|}{ NERVURA PRINCIPAL } \\
\hline & & estômatos & tricomas & organização & $\begin{array}{c}\mathrm{PP} \\
\left(\mathrm{n}^{0} \text { camadas }\right)\end{array}$ & $\begin{array}{c}\mathrm{PP} / \mathrm{PL} \\
(\%)\end{array}$ & esclereídes & IC & & IC & $\begin{array}{l}\text { sistema } \\
\text { vascular }\end{array}$ & $\begin{array}{l}\text { feixe } \\
\text { vascular }\end{array}$ \\
\hline \multicolumn{13}{|l|}{ Fabaceae } \\
\hline $\begin{array}{l}\text { Bowdichia } \\
\text { virgilioides }\end{array}$ & $A D$ & Hipo & + & Homo & $3-4$ & $100 / 0$ & - & - & Par & C & $A A$ & Co \\
\hline \multicolumn{13}{|l|}{ Malpighiaceae } \\
\hline $\begin{array}{l}\text { Byrsonima } \\
\text { coccolobifolia }\end{array}$ & $A B / A D$ & Hipo & - & Iso & 4 & $60 / 40$ & - & $C / D$ & Par & $\mathrm{C} / \mathrm{D}$ & $\mathrm{AF}$ & Co \\
\hline $\begin{array}{l}\text { Byrsonima } \\
\text { crassifolia }\end{array}$ & $A B / A D$ & Hipo & + & Iso & 4 & $75 / 25$ & - & $C / D$ & Par + Escl & $\mathrm{C} / \mathrm{D}$ & $\mathrm{AF}$ & Co \\
\hline $\begin{array}{l}\text { Byrsonima } \\
\text { verbascifolia }\end{array}$ & $\mathrm{AB} / \mathrm{AD}$ & Hipo & + & Iso & 3 & $50 / 50$ & - & $C / D$ & $\mathrm{Par}+\mathrm{Escl}$ & $\mathrm{C} / \mathrm{D}$ & AF & Co \\
\hline \multicolumn{13}{|l|}{ Salicaceae } \\
\hline Casearia sylvestris & $\mathrm{AB} / \mathrm{AD}$ & Anfi & + & Dorsi & 2 & $50 / 50$ & - & $\mathrm{C} / \mathrm{D}$ & - & $\mathrm{C} / \mathrm{D}$ & $\mathrm{AF}$ & Co \\
\hline \multicolumn{13}{|l|}{ Dilleniaceae } \\
\hline $\begin{array}{l}\text { Curatella } \\
\text { americana }\end{array}$ & $A B / A D$ & Hipo & + & Iso & 3 & $80 / 20$ & - & - & Par ou Escl & D & AA & Co \\
\hline \multicolumn{13}{|l|}{ Erythroxylaceae } \\
\hline $\begin{array}{l}\text { Erytroxylum } \\
\text { suberosum }\end{array}$ & $A D$ & Hipo & - & Dorsi & $2-3$ & $40 / 60$ & + & C & Par + Escl & C & $A A$ & Co \\
\hline \multicolumn{13}{|l|}{ Apocynaceae } \\
\hline $\begin{array}{l}\text { Himatanthus } \\
\text { articulatus }\end{array}$ & $A B / A D$ & Anfi & - & Dorsi & 2 & $45 / 55$ & - & $C / D$ & Par & C & $\mathrm{AF}$ & $\mathrm{Bi}$ \\
\hline \multicolumn{13}{|l|}{ Melastomataceae } \\
\hline Miconia albicans & $A D$ & Hipo & + & Dorsi & 1 & $60 / 40$ & - & $C / D$ & - & $\mathrm{C} / \mathrm{D}$ & $\mathrm{AA}$ & $\mathrm{Bi}$ \\
\hline \multicolumn{13}{|l|}{ Proteaceae } \\
\hline Roupala montana & $A B / A D$ & Hipo & + & Dorsi & $1-2$ & $45 / 55$ & + & - & Escl & - & $\mathrm{AF}$ & Co \\
\hline \multicolumn{13}{|l|}{ Annonaceae } \\
\hline Xylopia aromatica & $A B / A D$ & Hipo & + & Dorsi & $2-3$ & $70 / 30$ & - & - & Par & - & $\mathrm{AA}$ & Co \\
\hline
\end{tabular}

que ocupam mais de $50 \%$ do mesofilo (Tabela 2), e as células do parênquima lacunoso são irregulares, distribuídas em até quatro camadas de células. Roupala montana possui de uma a duas camadas de células longas no parênquima paliçádico e até sete camadas de células irregulares no parênquima lacunoso, e abundantes esclereídes são observados nas faces adaxial e abaxial. Outra espécie que apresenta esclereídes é $E$. suberosum, porém os mesmos são encontrados apenas na face adaxial (Figura 1B) (Tabela 2).

O mesofilo de Bo. virgilioides é homogêneo (Figura 3A), formado por três a quatro camadas de células paliçádicas. Para a maioria das espécies analisadas, foi constatado que o parênquima paliçádico corresponde a 50\% ou mais do mesofilo (Tabela 2).

Para todas as espécies, na região entre a nervura principal e o bordo, os feixes vasculares são colaterais e de vários tamanhos. As nervuras secundárias de nove espécies são envolvidas por uma bainha de células parenquimáticas e/ou esclerenquimáticas que formam extensão de bainha (Figuras $1 \mathrm{E}, 1 \mathrm{G})$ (Tabela 2). Essas extensôes estáo ausentes em $C$. sylvestris e $M$. albicans.

$\mathrm{Na}$ nervura principal, as espécies apresentam o sistema vascular do tipo colateral, exceto em $H$. articulatus (Figura 3C) e M. albicans (Figura 3D) nas quais é bicolateral disposto em forma de arco fechado ou aberto (Figuras 3C-3K) (Tabela 2). Em $H$. articulatus apresenta-se circundado por várias camadas de fibras. Uma bainha cristalífera contendo cristais prismáticos e drusas envolve o sistema vascular de Bo. virgilioides, By. coccolobifolia, By.crassifolia, Ca. sylvestris (Figura 3L), E. suberosum e $R$. montana. O formato da nervura principal é variável, côncavo/ convexo em Bo. virgilioides e $M$. albicans, plano-convexo em $R$. montana e $X$. aromatica, levemente convexo/côncavo em $E$. suberosum e convexo/côncavo nas outras seis espécies. Na nervura principal, a cutícula é espessa em Bo. virgilioides, By. crassifolia (Figura 3G), By. verbascifolia, Ca. sylvestris, $H$. articulatus, $R$. 


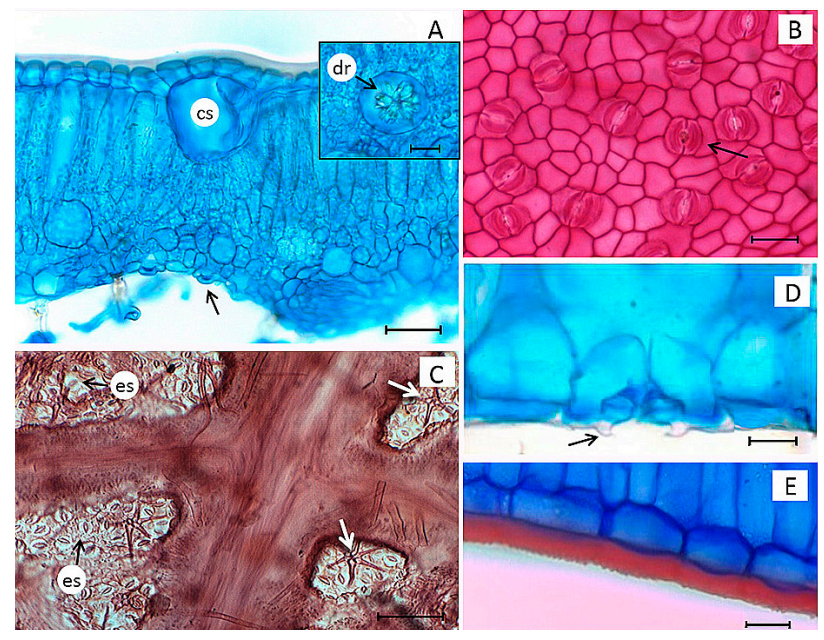

Figura 2. Cortes transversais (A, D-E) ou vista frontal $(B, C)$ mostrando: $(A)$ cavidade secretora, face abaxial com estômato levemente projetado em relação às demais células epidérmicas (seta) e, no detalhe, idioblasto cristalífero em Miconia albicans; (B) estômatos do tipo anomocítico (seta) na epiderme abaxial de Byrsonima coccolobifolia; (C) distribuição dos estômatos e tricoma estrelado (seta branca) na face abaxial de Curatella americana; (D) estômato com cristas supraestomáticas (seta) na face abaxial de Byrsonima coccolobifolia; (E) epiderme com cutícula estriada em Himatanthus articulatus. $c S=$ cavidade secretora, $\mathrm{dr}=$ drusa, es = estômato. Barras $=20 \mu \mathrm{m}(\mathrm{A}, \mathrm{B}) ; 50 \mu \mathrm{m}(\mathrm{C}) ; 10$ $\mu \mathrm{m}(\mathrm{D}, \mathrm{E}$, detalhe em A). Esta figura é colorida na versão eletrônica.

montana, X. aromatica, By. coccolobifolia e M. albicans, e delgada em $\mathrm{Cu}$. americana e E. suberosum.

Idioblastos cristalíferos estão presentes no mesofilo ou na nervura principal de nove das onze espécies, as exceçóes foram $R$. montana $X$. aromatica (Tabela 2). Foram observados compostos fenólicos em Bo. virgilioides, By. crassifolia, By. coccolobifolia, By. verbascifolia, E. suberosum, M. albicans, $R$. montana e $X$. aromatica. Nas espécies $C a$. sylvestris, $M$. albicans e $X$. aromatica ocorrem cavidades secretoras que estão distribuídas ao acaso por todo o mesofilo. Estas são heterodimensionais, arredondadas ou ovais (Figura 2A).

\section{DISCUSSÃO}

A análise da anatomia foliar das onze espécies estudadas mostra que estas possuem um conjunto bem definido de atributos anatômicos, que são característicos de plantas de ambientes xerófilos, sujeitos a elevada temperatura e luminosidade e a baixa umidade relativa do ar, condiçóes predominantes nos ecossistemas de savanas. Todas as espécies apresentam epiderme adaxial com cutícula espessa, sendo que oito delas mostraram espessamento em ambas as faces. A cutícula é constituída por substâncias lipídicas, como cera e cutina, com função de reduzir a difusão de vapor de água dos tecidos internos da folha para a atmosfera (Burghardt e Riederer 2006; Larcher 2006). O espessamento dessa camada aumenta a resistência à perda de água pela superfície

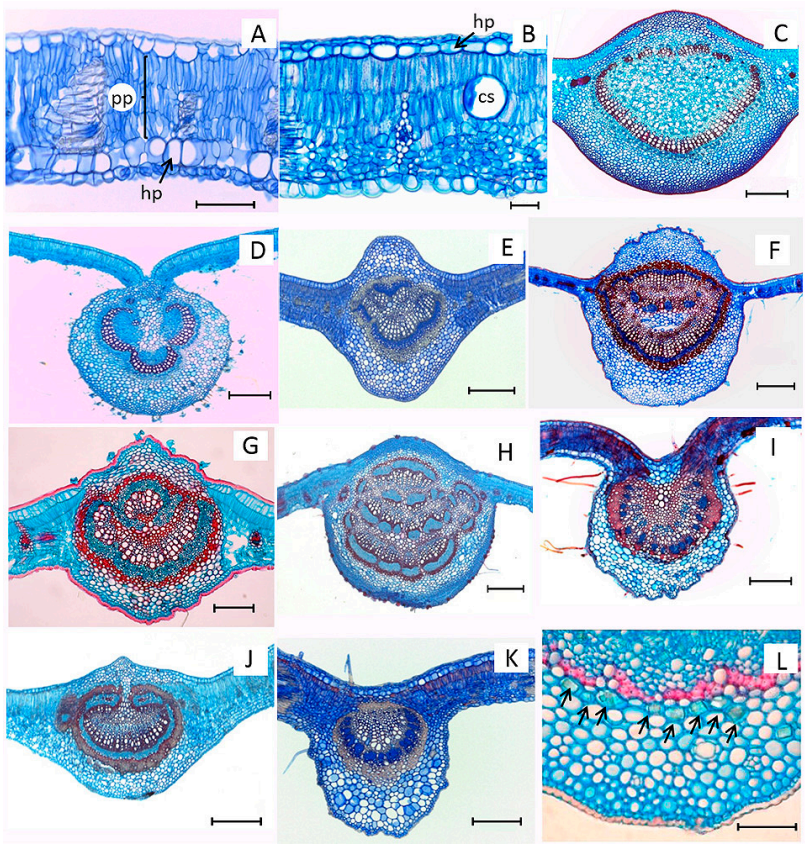

Figura 3. Cortes transversais mostrando: (A) mesofilo homogêneo em Bowdichia virgilioides, com três camadas de células do parênquima paliçádico (chave) e hipoderme (seta) na face abaxial; (B) mesofilo dorsiventral em Xylopia aromatica, com cavidades secretoras e hipoderme na face adaxial. (C) Nervura principal de Himatanthus articulatus com sistema vascular em arco fechado; (D) nervura principal com formato convexo/côncavo, sistema vascular em arco aberto e feixes bicolaterais em Miconia albicans; (E) nervura principal com formato convexo/côncavo e sistema vascular em arco fechado em Byrsonima coccolobifolia, (F) Byrsonima verbascifolia, (G) Byrsonima crassifolia e (H) Curatella americana; (I) formato côncavo/convexo e sistema vascular em arco fechado em Bowdichia virgilioides; (J) formato levemente convexo/côncavo e sistema vascular em arco fechado em Erytroxylum suberosum; (K) formato plano convexo e sistema vascular em arco fechado em Xylopia aromatica. (L) Cutícula densamente espessa, presença de cristais (seta) na região do parênquima que envolve o sistema vascular de Casearia sylvestris. cs = cavidade secretora, $h p=$ hipoderme, $\mathrm{pp}=$ parênquima paliçádico. Barras $=50 \mu \mathrm{m}(\mathrm{A}, \mathrm{D}, \mathrm{L}) ; 20 \mu \mathrm{m}$ (B); $200 \mu \mathrm{m}$ (C, E, F, G, H, K, J); $100 \mu \mathrm{m}$ (I). Esta figura é colorida na versão eletrônica.

foliar, ou seja, contribui para reduzir a transpiração cuticular e pode elevar a eficiência no uso de água nestas plantas. Cutículas espessas também podem oferecer proteçáo contra altas intensidades luminosas e radiaçáo ultravioleta (Cen e Bornman 1993; Krauss et al. 1997).

A epiderme é um tecido multifuncional formado por diferentes tipos de células especializadas, como as que constituem os estômatos e os tricomas, cuja estrutura e localização influenciam nas relaçóes hídricas e nas trocas gasosas que ocorrem nas folhas. A classificação dos estômatos mostrou variabilidade entre os tipos existentes, podendo mais de um tipo estar presente na mesma epiderme. Porém, a localização predominante na face abaxial, algumas vezes encobertos por tricomas, ou a formaçáo em determinadas 
espécies de uma câmara supraestomática, característica geralmente observada em epífitas de ecossistemas secos, é considerada uma estratégia para reduzir a transpiração (Rasmunssen 1987). Em Cu. americana e M. albicans, a presença de densos indumentos na epiderme pode representar uma importante adaptação a ambientes xéricos, tendo em vista que essas estruturas aumentam a reflexão da irradiação solar (Holmes e Keiler 2002) e podem, portanto, contribuir para a diminuição da temperatura foliar (Ehleringer e Mooney 1978; Ehleringer 1983). A presença de tricomas na epiderme também contribui para um aumento da espessura da camada de ar parado revestindo a superfície da folha e, como consequência, restringe a perda de vapor de água dos estômatos para a atmosfera (Fahn e Cutler 1992; Larcher 2006). Adicionalmente, pode oferecer proteção contra herbivoria (Woodman e Fernandes 1991) ou ao ataque de patógenos (Valkama et al. 2005).

Características da anatomia da folha, como o número expressivo de camadas células do parênquima paliçádico, dorsiventral ou isobilateral, preenchendo grande parte do espaço no mesofilo nas onze espécies analisadas, mostra investimento destas em tecidos fotossintéticos, o que é característico de plantas expostas a altas intensidades luminosas (Metcalfe 1983; Fahn e Cutler 1992). Além disso, mais de 80\% das espécies apresentou uma extensão da bainha de feixes, estrutura que tem sido relacionada ao transporte de água, resistência mecânica, mas também a uma maior eficiência fotossintética na utilização da energia luminosa pelas plantas. As células parenquimáticas da extensão da bainha possuem paredes celulares delgadas e sem conteúdo celular aparente, o que, de acordo com Karabourniotis et al. (2000), lhes conferiria a capacidade de filtrar a luz incidente e transferi-la, enriquecida principalmente com os comprimentos de onda azul e vermelho do espectro luminoso, aumentando portanto a disponibilidade de luz na faixa fotossinteticamente ativa para as camadas mais internas do mesofilo, sendo este fenômeno mais acentuado em folhas compactas e grossas.

O acúmulo de cristais de oxalato de cálcio ocorre com frequência nos tecidos foliares das plantas de savanas. Alguns autores sugerem que desempenhem um papel de defesa contra herbivoria, pois reduziriam a digestibilidade das folhas ou, dependendo do tipo/forma, poderiam levar à morte do herbívoro (Konno et al. 2014). Entretanto, vale ressaltar que o papel central dos cristais de oxalato de cálcio em plantas de ambientes sazonais ainda não está totalmente elucidado (Franceschi e Nakata 2005), sendo provável que, para as espécies em estudo, esteja relacionado a mais de uma função na proteção do tecido foliar. Cerca de $60 \%$ das plantas estudadas apresentaram cristais prismáticos e drusas no mesofilo, e mais de $80 \%$ mostrou estas estruturas nas células parenquimáticas próximas à região das nervuras. É provável que a presença expressiva de cristais nessa regiáo ocorra porque o xilema é o principal tecido de entrada de íons de cálcio $\left(\mathrm{Ca}^{+}\right)$, e a precipitação na forma de cristais em torno das nervuras impediria o acúmulo deste nutriente em sua forma iônica na célula, o que poderia comprometer a regulação e a integridade de processos celulares (Franceschi e Nakata 2005).

Embora as espécies analisadas sejam comuns a outros ecossistemas de savanas distribuídos ao longo do Brasil, e algumas com a anatomia bem documentada, especialmente dentro do Bioma Cerrado (Bieras e Sajo 2009; Rossatto et al. 2010; Araújo et al. 2010), caracteres importantes para a manutenção do balanço hídrico e luminoso, como cutícula espessa e o número de camadas do mesofilo, são plásticos, podendo diferir entre populaçôes de espécies que colonizam locais com diferentes pressóes ambientais. Ao avaliar a anatomia das onze espécies, foi possível verificar que, de fato, algumas delas apresentam estruturas que diferem das descriçōes encontradas na literatura (Bieras e Sajo 2009; Machado et al. 2013) para essas mesmas espécies no Cerrado. Estudos que se referem à anatomia foliar de Bo. virgilioides descrevem a organizaçáo do mesofilo desta espécie como dorsiventral (Bieras e Sajo 2009; Machado et al. 2013). No entanto, Bo. virgilioides que ocorre nas savanas de Roraima apresenta mesofilo homogêneo. Atributo comumente relatado como resposta de tolerância à seca e a altas intensidades luminosas. Nessa espécie, o parênquima possui poucos espaços intercelulares, mas, aparentemente, a redução na capacidade de absorver dióxido de carbono é compensada pelo benefício obtido na conservação da água nos tecidos (Mauseth 1988). Entre as arbóreas encontradas nas savanas de Roraima, $\mathrm{Cu}$. americana tem especial destaque pela frequência com que ocorre (Miranda e Absy 2000; Barbosa e Fearnside 2004). Estudos realizados nas savanas da Venezuela relatam que essa espécie possui alta eficiência intrínseca no uso da água, especialmente nos períodos de maior déficit hídrico, além de manter a taxa de fotossíntese elevada e resistir a baixos potenciais hídricos foliares (Medina e Francisco 1994). A análise anatômica de suas folhas esclarece como o arranjo dos tecidos pode auxiliar a enfrentar os distintos estresses do ambiente. $\mathrm{Cu}$. americana coletada em Roraima possui mesofilo isobilateral, diferente do observado para essa espécie em outras savanas do Brasil, em que a organizaçáo do mesofilo aparece como dorsiventral (Bieras e Sajo 2009), com as células paliçádicas ocupando a maior parte do espaço do mesofilo. A posição dos estômatos de $\mathrm{Cu}$. americana, na face abaxial, situados entre as nervuras e dispostos em densos agrupamentos, pode influenciar na condutância estomática e velocidade de perda de água pela planta. A proximidade entre os estômatos e, como consequência, das câmaras subestomáticas pode causar uma sobreposição das rotas de difusão de vapor de água, do interior do mesofilo para a atmosfera, dificultando 
a saída de água da planta e, como consequência, reduzindo a transpiração (Larcher 2006).

Embora seja um órgão com elevado grau de plasticidade, alguns dos caracteres ou estruturas presentes na folha são bastante conservados e utilizados em estudos de taxonomia (Metcalfe e Chalk 1950; Araújo et al. 2010). A presença de células papilosas é característica de certas espécies de Erytroxylum (Araujo et al. 2014), no entanto, a existência dessa estrutura em E. suberosum é controversa. Bieras e Sajo (2004) sugeriram que, pelo padrão que apresentavam, as projeçôes observadas na epiderme foliar da espécie seriam depósitos de cera, ao contrário do relatado por Salatino et al. (1986). Porém, no presente estudo, para as plantas coletadas em Roraima, está claro que as projeçôes observadas em E. suberosum são papilas, e muito se assemelham àquelas descritas por Salatino et al. (1986), referidas como células papilosas em forma de cúpula.

Se por um lado as características constitutivas presentes nas plantas podem ser utilizadas para diferenciar espécies dentro de um táxon, por outro podem ser vistas como mais um fator que está favorecendo o estabelecimento destas em determinados ambientes. No caso de E. suberosum, a presença de papilas nas células da epiderme não seria apenas um atributo filogenético, pois alguns autores sugerem que também podem refletir a irradiação solar (Alquini et al. 2003), afetando o balanço de energia da folha.

Do mesmo modo, estruturas relacionadas ao armazenamento de água nos tecidos, como a hipoderme presente em $B o$. virgilioides (Morretes 1958) e X. aromatica (Metcalfe e Chalk 1950; Bieras e Sajo 2009), e a estratificaçáo das epidermes nas espécies de Byrsonima que contribui para restringir a transpiração, são caracteres taxonômicos utilizados para separar espécies dentro dos gêneros (Metcalfe e Chalk 1950; Araújo et al. 2010), mas que também têm uma função adaptativa.

\section{CONCLUSÃO}

A anatomia da lâmina foliar, das espécies lenhosas mais frequentes nas savanas de Roraima, indica a existência de uma marcada síndrome adaptativa a ambientes xéricos. Esta é caracterizada pela presença de uma cutícula espessa na face adaxial, densos indumentos, localização dos estômatos na face abaxial, a presença de hipoderme ou de uma epiderme estratificada e cristais na região das nervuras. Além disto, extensão da bainha de feixes caracteriza nove das onze espécies estudadas, e em oito espécies há um investimento pronunciado em parênquima paliçádico em detrimento de lacunoso. Muitos destes caracteres exercem mais de uma função adaptativa, como tricomas e cristais, que, associados a compostos fenólicos presentes na maioria das espécies, oferecem uma proteção adicional contra a herbivoria ou ao ataque de patógenos.

\section{AGRADECIMENTOS}

Ao Conselho Nacional de Desenvolvimento Científico e Tecnológico (Processos 484545/2012-4, 303637/2011-0 e 309465/2012-5) e a Coordenação de Aperfeiçoamento de Pessoal de Nível Superior, por meio do Programa Nacional de Apoio e Desenvolvimento da Bôtanica (CAPES/PNADB/ AUXPE 451/2010), que financiaram a pesquisa. À Embrapa Roraima e ao Dr. Reinaldo Imbrozio Barbosa pelo apoio logístico em Boa Vista.

\section{BIBLIOGRAFIA CITADA}

Alquini, Y.; Bona, C.; Boeger, M.R.T.; Costa, C.G.; Barros, C.F. 2003. Epiderme. In: Appezzato-da-Glória, B.; Carmello-Guerreiro, S.M. (Ed.). Anatomia Vegetal. Viçosa: UFV, p.88 - 107.

Araújo, A.C.O.; Barbosa, R.I. 2007. Riqueza e diversidade do estrato arbóreo-arbustivo de duas áreas de savanas em Roraima, Amazônia brasileira. Mens Agitat, 2: 11-18.

Araújo, J.S.; Azevedo, A.A.; Silva, L.C.; Meira, R.M.S.A. 2010. Leaf anatomy as an additional taxonomy tool for 16 species of Malpighiaceae found in the Cerrado area (Brazil). Plant Systematics and Evolution, 286: 117-131.

Araujo, T.F.; Fiasch, P.; Amorim, A.M. 2014. Erythroxylum (Erythroxylaceae) na Mata Atlântica da Bahia, Brasil. Rodriguésia, 65: 637-658.

Barbosa, R.I.; Campos, C. 2011. Detection and geographical distribution of clearing areas in the savannas (lavrado) of Roraima using Google Earth web tool. Journal of Geography and Regional Planning, 4: 122-136.

Barbosa, R.; Fearnside, P.M. 2004. Wood density of trees in open savannas of the Brazilian Amazon. Forest Ecology and Management, 115-123.

Barbosa, R.I.; Campos, C.; Pinto, F.; Fearnside, P.M. 2007. The "Lavrados" of Roraima: Biodiversity and Conservation of Brazil's Amazonian Savannas. Functional Ecosystems and Communities, 1: 29-41.

Bieras, A.C.; Sajo, M.G. 2004. Anatomia foliar de Erythroxylum P. Browne (Erythroxylaceae) do Cerrado do Estado de São Paulo, Brasil. Acta Botanica Brasilica, 18: 601-612.

Bieras, A.C.; Sajo, M.G. 2009. Leaf structure of the cerrado (Brazilian savanna) woody plants. Trees, 23: 451-471.

Burghardt, M.; Riederer, M. 2006. Cuticular transpiration. In: Riederer, M.; Müller, C. (Ed.). Biology of the Plant Cuticle. Blackwell, Oxford, UK, p.292-311.

Cen, Y.P.; Bornman, J. 1993. The effect of exposure to enhanced UV-B radiation on the penetration of monochromatic and polychromatic UV-B radiation in leaves of Brassica napus. Physiologia Plantarum, 87: 249-255.

Ehleringer, J.R. 1983. Characterization of a glabrate Encelia farinosa mutant: morphology, ecophysiology, and field observations. Oecologia, 57: 303-310.

Ehleringer, J.R.; Mooney H.A. 1978. Leaf Hairs: Effects on Physiological Activity and Adaptive Value to a Desert Shrub. Oecologia, 37: 183-200. 
Eiten, G. 1972. The cerrado vegetation of Brazil. Botanical Review, 38: 201-341.

Evert, R. F. 2006. Esau's Plant Anatomy: Meristems, Cells, and Tissues of the Plant Body: Their Structure, Function, and Development. Wiley-Interscience, New Jersey, 601p.

Fahn, A.; Cutler, D.F. 1992. Xerophytes. Berlin, Gebrüder Borntraeger, 176p.

Foldats, E.; Rutkis, E. 1975. Ecological studies of chaparro (Curatella americana L.) and manteco (Byrsonima crassifolia H.B.K) in Venezuela. Journal of Biogeography, 2: 159-178.

Franceschi, V.R.; Nakata, P.A. 2005. Calcium Oxalate in Plants: Formation and Function. Annual Review of Plant Biology, 56: 41-71.

Holmes, M.G.; Keiller, D.R. 2002. Effects of pubescence and waxes on the reflectance of leaves in the ultraviolet and photosynthetic wavebands: a comparison of a range of species. Plant, Cell and Environment, 25: 85-93.

Jensen, W.A. 1962. Botanical histochemistry (principles and pratice). San Francisco: W.H. Freeman and Company, 408p.

Johansen, D.A. 1940. Plant Microtechnique. McGraw-Hill, New York, 523p.

Karabourniotis, G.; Bornman, J.F.; Nikolopoulos, D. 2000. A possible optical role of the bundle sheath extensions of some heterobaric leaves. Plant, Cell and Environment, 23: 423-430.

Krauss, P., Markstadter, C., Riederer, M. 1997. Attenuation of UV radiation by plant cuticles from woody species. Plant, Cell and Environment, 20: 1079-1085.

Kraus, J.E.; Arduin, M. 1997. Manual básico de métodos em morfologia vegetal. Rio de Janeiro, Edur, 198p.

Konno, K.; Inoue1, T.A.; Nakamura, M. 2014. Synergistic defensive function of raphides and protease through the needle effect. PLoS ONE, 9(3): e91341.

Larcher, W. 2006. Ecofisiologia Vegetal. São Paulo, RIMA, 550p.

Luque, R.; Sousa, H.C.; Kraus, J.E. 1996. Métodos de coloraçáo de Roeser (1972) - modificado - e Kropp (1972) visando a substituição do azul de astra por azul de alcião 8GS ou 8GX. Acta Botanica Brasilica, 10: 199-212.

Machado, V.M.; Santos, J.B.; Pereira, I.M.; Lara, R.O.; Cabral, C.M.; Amaral, C.S. 2013. Sensibilidade de mudas de espécies florestais nativas ao glyphosate. Bioscience Journal, 29: 1941-1951.

Mauseth, J.D. 1988. Plant anatomy. The Benjamin/Cummings Publishing Company, Inc., Menlo Park, California, 560p.

Meneses, M.E.N.S.; Costa, M.L.; Behling, H. 2013. Late Holocene vegetation and fire dynamics from a savanna - forest ecotone in Roraima state, northern Brazilian Amazon. Journal of South American Earth Sciences, 42: 17-26.
Medina, E.; Francisco, M. 1994. Photosynthesis and water relations of savanna tree species differing in leaf phenology. Tree Physiology, 14: $1367-1381$.

Metcalfe, C.R. 1983. Secreted mineral substances. In: Metcalfe, C.R.; Chalk, L. (Ed.). Anatomy of the dicotyledons. Wood structure and conclusion of the general introduction. Clarendon Press, Oxford, p.82-97.

Metcalfe, C.R.; Chalk, L. 1950. Anatomy of the dicotyledons: leaves, stem, and wood in relation to taxonomy with notes on economic uses, Vol. 2. Oxford: Claredon Press, 1500p.

Miranda, I.S.; Absy, M.L. 2000. Fisionomia das Savanas de Roraima. Acta Amazonica, 30: 423-440.

Morretes, B. L. 1958. Contribuição ao estudo da anatomia das folhas de plantas do cerrado. Boletim da Faculdade de Filosofia, Ciências e Letras, Universidade de São Paulo, 15: 7-70.

Paiva, J.G.A.; Fank-De-Carvalho, S.M.; Magalhães, M.P.; GracianoRibeiro, D. 2006. Verniz vitral incolor 500: uma alternativa de meio de montagem economicamente viável. Acta Botanica Brasilica, 20: 257-264.

Rasmunssen, H. 1987. Orchid stomata - structure, differentiation, function, and phylogeny. In: Arditti, J. (Ed.). Orchid Biology: Reviews and Perspectives, IV. Cornell University Press, New York, p.105-138.

Ribeiro, J.F.; Walter, B.M.T. 1998. Fitofisionomias do Bioma Cerrado. In: Sano, S.M.; Almeida, S.P. (Ed.). Cerrado Ambiente e Flora. Planaltina: Embrapa CPAC. p.89-152.

Rossatto, D.R.; Takahashi, F.S.C.; Silva, L.C.; Franco, A.C. 2010. Características funcionais de folhas de sol e sombra de espécies arbóreas em uma mata de galeria no Distrito Federal, Brasil. Acta Botanica Brasilica, 24: 640-647.

Salatino, A.; Montenegro, G.; Salatino, M.L.F. 1986. Microscopia eletrônica de varredura de superfícies foliares de espécies lenhosas do cerrado. Revista Brasileira de Botanica, 9: 117-124

Schaefer, C.E.R.G.; Dalrymple, J.B. 1996. Pedogensis and relict properties of soil with columnar structure. Geoderma, 71: 1-17.

Valkama, E.; Koricheva, J.; Salminen, J.P.; Helander, M.; Saloniemi, I.; Saikkonen, K.; Pihlaja, K. 2005. Leaf surface traits: overlooked determinants of birch resistance to herbivores and foliar microfungi? Trees, 19: 191-197.

Woodman, R.L.; Fernandes, G.W. 1991. Differential mechanical defense: herbivory, evapotranspiration, and leaf-hairs. OIKOS, 60: $11-19$

Recebido em 30/01/2015

Aceito em 14/05/2015 